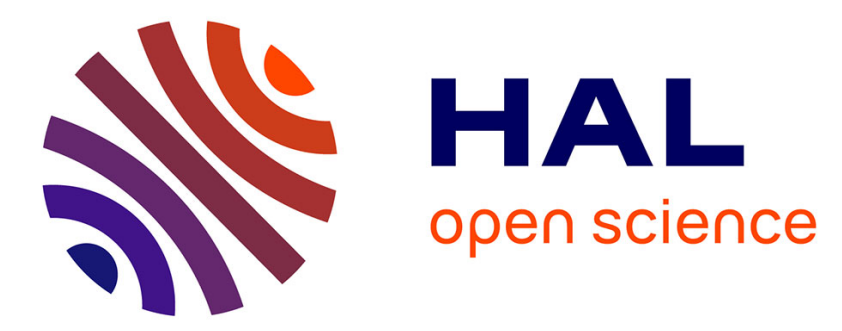

\title{
Synchrotron-based Mössbauer spectroscopy characterization of sublimated spin crossover molecules
} Alberto Cini, Lorenzo Poggini, Alexander Chumakov, Rudolf Ruffer, Gabriele Spina, Alain Wattiaux, Mathieu Duttine, Mathieu Gonidec, Maria Fittipaldi, Patrick Rosa, et al.

\section{To cite this version:}

Alberto Cini, Lorenzo Poggini, Alexander Chumakov, Rudolf Ruffer, Gabriele Spina, et al.. Synchrotron-based Mössbauer spectroscopy characterization of sublimated spin crossover molecules. Physical Chemistry Chemical Physics, 2020, 22 (12), pp.6626-6637. 10.1039/C9CP04464G . hal02558753

\section{HAL Id: hal-02558753 \\ https://hal.science/hal-02558753}

Submitted on 9 Jun 2020

HAL is a multi-disciplinary open access archive for the deposit and dissemination of scientific research documents, whether they are published or not. The documents may come from teaching and research institutions in France or abroad, or from public or private research centers.
L'archive ouverte pluridisciplinaire HAL, est destinée au dépôt et à la diffusion de documents scientifiques de niveau recherche, publiés ou non, émanant des établissements d'enseignement et de recherche français ou étrangers, des laboratoires publics ou privés. 


\title{
PAPER
}

\section{Synchrotron-based Mössbauer spectroscopy characterization of sublimated spin crossover molecules $\dagger$}

\author{
Alberto Cini, (D) $\ddagger^{\mathrm{a}}$ Lorenzo Poggini, (I) $\ddagger^{\mathrm{b}}$ Alexander I. Chumakov, ${ }^{\mathrm{c}}$ Rudolf Rüffer, ${ }^{\mathrm{c}}$ \\ Gabriele Spina, ${ }^{a}$ Alain Wattiaux, ${ }^{\mathrm{b}}$ Mathieu Duttine, ${ }^{\mathrm{b}}$ Mathieu Gonidec, (D) b \\ Maria Fittipaldi, (D) *a Patrick Rosa (D) ${ }^{* b}$ and Matteo Mannini (D) *d
}

\begin{abstract}
The spin crossover $(\mathrm{SCO})$ efficiency of $\left[{ }^{57} \mathrm{Fe}(\mathrm{bpz})_{2}(\right.$ phen)] (where bpz $=$ bis(pyrazol-1-y 1 )borohydride and phen $=$ 9,10-phenantroline) molecules deposited on gold substrates was investigated by means of synchrotron Mössbauer spectroscopy. The spin transition was driven thermally, or light induced via the LIESST (light induced excited spin-state trapping) effect. Both sets of measurements show that, once deposited on a gold substrate, the efficiency of the SCO mechanism is modified with respect to molecules in the bulk phase. A correlation in the distribution of hyperfine parameters in the sublimated films, not evidenced so far in the bulk phase, is reported. This translates into geometrical distortions of the first coordination sphere of the iron atom that seem to correlate with the decreased spin conversion. The work reported clearly shows the potentiality of synchrotron Mössbauer spectroscopy for the characterization of nanostructured Fe-based SCO systems, thus resulting as a key tool in view of their applications in innovative nanoscale devices.
\end{abstract}

\section{Introduction}

The spin crossover (SCO) effect, namely reversible switching between low spin (LS) and high spin (HS) states, can be observed in transition-metal ion complexes $\left(d^{4}\right.$ to $\left.d^{7}\right),{ }^{1,2}$ forming bistable systems. These can be switched with a variety of external stimuli, such as temperature, ${ }^{3,4}$ light $^{5-8}$ pressure, $^{9}$ and magnetic ${ }^{10}$ or electric fields. ${ }^{11}$ The external stimulus influences the competition between the ligand-field strength and the spin-pairing energy, responsible for the bistability of the system. ${ }^{1,2}$ Moreover, SCO can be induced at low temperature (usually below ca. $20 \mathrm{~K}$ ) from the LS state to a metastable HS state with typical lifetimes ranging from minutes to hours and even days. ${ }^{12-15}$

The variety of switching stimuli permitting to induce SCO, thus controlling the spin state of the system, makes SCO

\footnotetext{
a Department of Physics and Astronomy, University of Florence and INSTM Research Unit of Florence, via Sansone 1, I 50019 Sesto Fiorentino (FI), Italy. E mail: maria.fittipaldi@unifi.it

${ }^{b}$ CNRS, Univ. Bordeaux, Bordeaux INP, ICMCB, UMR 5026, F 33600 Pessac, France. E mail: patrick.rosa@icmcb.cnrs.fr

${ }^{c}$ ESRF The European Synchrotron, 71, Avenue des Martyrs, Grenoble, France

"Department of Chemistry "Ugo Schiff", University of Florence and INSTM Research Unit of Florence, via della Lastruccia 3 13, I 50019 Sesto Fiorentino (FI), Italy. E mail: matteo.mannini@unifi.it

$\dagger$ Electronic supplementary information (ESI) available: Fig. S1 S26; Tables S1 S14; Notes S1 S3. See DOI: 10.1039/c9cp04464g

\# These two authors contributed equally to the manuscript.
}

molecules promising building blocks in the field of spintronics, ${ }^{16-18}$ as well as potential elements for displays and sensors. ${ }^{19,20}$ An accurate evaluation of the conditions in which SCO systems can maintain their behaviour when deposited on a solid substrate is a fundamental prerequisite to the development of SCO-based nanoscale devices ${ }^{21-30}$ and appropriate tools must be developed in order to properly study these systems when only a small number of molecules is considered. This paper addresses this last issue by proposing the use of Mössbauer spectroscopy based on the Synchrotron Mössbauer Source (SMS hereafter) set up at ID18, the Nuclear Resonance Beamline ${ }^{31}$ of the European Synchrotron Radiation Facility (ESRF), as an advanced tool for the characterization of thin SCO films. ${ }^{32}$

Recent investigations of ultra-thin layers of SCO molecules deposited on several substrates indicate that strong modifications of their properties can occur with the possible coexistence of the two spin states and even a partial loss of the spin switching properties. ${ }^{21-30,33-39}$ Thus the SCO behaviour in these molecules depends strongly on the interaction with the substrate, which can be further altered by attaching different substituents to the ligands. ${ }^{40}$ Furthermore, it has been noticed that the SCO features depend on the environment surrounding the molecule: ${ }^{41}$ cooperative intermolecular interactions, ${ }^{42-44}$ favoured for example by hydrogen bonding or $\pi-\pi$ stacking, ${ }^{45}$ can take part in the SCO phenomenon in the solid state, as well as in thin sublimated films depending on the molecular reorganization in the film. 
An important class of SCO molecules is represented by complexes based on iron(II) often arranged in a distorted-octahedral coordination environment. . $^{1,43,44,46,47}$ The presence of the iron atom allows one to study the SCO process using ${ }^{57} \mathrm{Fe}$ Mössbauer spectroscopy, enabling one to readily estimate the LS and HS percentage as a function of temperature, ${ }^{32,48}$ pressure $^{9,32,49-51}$ and light irradiation, ${ }^{5,32,52}$ as well as to deeply characterize the electronic structure of each spin state and eventually the modifications induced by specific alteration in the molecular structure. ${ }^{5}$ It is worth noticing that the sensitivity of a standard setup based on a radioactive source is suitable, for molecules, mainly to study the bulk phase. This limitation is overcome in synchrotron-based Mössbauer experiments, ${ }^{32}$ taking advantage of a grazing incidence geometry, an approach that recently has been adopted by some of us to collect energy-domain spectra of thin films of magnetic molecules chemisorbed on a substrate..$^{53}$

Here, as a proof of concept of the capabilities of this technique to investigate SCO complexes, we report the characterization of thin and ultra-thin films of one of the most studied Fe(II)-based SCO systems, ${ }^{24,26,47,54-60}$ namely $\left[\mathrm{Fe}(\mathrm{bpz})_{2}(\mathrm{phen})\right]$ (1) where bpz = bis(pyrazol-1-yl)borohydride and phen = 9,10-phenantroline, fully ${ }^{57} \mathrm{Fe}$ enriched, ${ }^{57} \mathbf{1}$ hereafter, and deposited by thermal sublimation on polycrystalline $\mathrm{Au}$ substrates. Three samples with different thicknesses of the deposited molecules down to a few nm were investigated and the SCO phenomenon was studied both as a function of temperature and light irradiation (LIESST effect).

\section{Methods}

\section{Sample preparation}

Compound ${ }^{57} \mathbf{1}$ was synthesized as single crystals by following literature procedures, ${ }^{58}$ starting from ${ }^{57} \mathrm{FeCl}_{2}$ obtained by the controlled oxidation of metallic ${ }^{57} \mathrm{Fe}$ foil with $\mathrm{HCl}$. The identity of ${ }^{57} 1$ was checked by comparing unit cell parameters measured by X-ray diffraction against reported values. ${ }^{55}$ Moreover, Raman spectra of enriched and natural abundance 1 (Fig. S1 in the ESI $\dagger$ ) showed identical spectra with respect to both peak energies and lineshapes. The preservation of the SCO behaviour was checked by standard Mössbauer spectroscopy (Fig. S2-S4 in the ESI $\dagger$ ) and by standard magnetometry (Fig. S5 in the ESI $\dagger$ ). Magnetometry and Raman (Fig. S6 in the ESI $\dagger$ ) were also measured on the powder obtained after drying a $\mathrm{CHCl}_{3}$ solution of ${ }^{57} \mathbf{1}$, in order to check the chemical integrity of ${ }^{57} \mathbf{1}$ and the preservation of SCO upon dissolution. The thin films of ${ }^{57} \mathbf{1}$ on a gold substrate were obtained by thermal sublimation in a high vacuum (HV), with a thickness of $50 \mathrm{~nm}$ and $5 \mathrm{~nm}$. A thicker and less homogeneous deposit was also obtained by drop-casting a $0.5 \mathrm{mM}$ solution in $\mathrm{CH}_{2} \mathrm{Cl}_{2}$ of ${ }^{57} 1$ on the same substrate.

\section{SMS characterization}

Nanostructured samples were investigated by taking advantage of the Synchrotron Mössbauer Source set up at ID18 of ESRF. One of the peculiarities of the SMS is the possibility to investigate thin films down to a single molecular layer, ${ }^{53}$ which is obtained by extreme care in the collimation of the high photon flux of the synchrotron radiation and multi-step monochromatization, the peculiar part of which is the nuclear resonant monochromator obtained with a ${ }^{57} \mathrm{FeBO}_{3}$ single crystal, ${ }^{61,62}$ combined with a grazing incidence geometry.

Due to the structure of our samples (low- $Z$ film on a high- $Z$ substrate, $Z$ being the atomic number), grazing incidence reflection occurs at the substrate surface, and the molecular layer produces absorption lines. In the case of small grazing angles, the spectra can be treated as those obtained in a standard setup in transmission geometry, provided that the effective thickness of the samples is multiplied by a factor $2 / \sin \theta$. Here the effective thickness is a dimensionless parameter that takes into account the number of Mössbauer active nuclei encountered by the radiation along its path in the sample, $\theta$ is the grazing angle between the surface of the sample and the direction of the incoming radiation, and the factor $2 / \sin \theta$ accounts for the path lengths of both the incident and reflected radiation inside the molecular layer. In our experimental conditions, working at $\theta \sim 0.1^{\circ}$ provides a thousandfold amplification factor with respect to a standard experiment performed at normal or close to normal incidence. This amplification effect allows the characterization of ultrathin molecular films containing ${ }^{57} 1$ molecules, therefore allowing us to follow the spin transition in nanostructured samples by varying the temperature, provided that the two following hypotheses are fulfilled: (i) the increases of metal-ligand bond lengths do not change significantly the temperature dependences of recoilless fraction parameters $(f)^{63}$ for both the HS and LS states and (ii) the spin state lifetimes are outside the Mössbauer time window.

The thermal SCO, as well as the occurrence of the light induced excited spin-state trapping (LIESST) effect, was investigated by collecting the Mössbauer spectra of the samples as a function of the temperature and of irradiation performed in situ (see Experimental for details).

\section{Mössbauer spectra analysis}

A quantitative assessment of spin states fractions required the evaluation of the Mössbauer absorption cross-section of the samples (see Experimental for details). At each temperature, each spectrum has been analysed as resulting from the convolution of an HS and an LS contribution. Both were characterized by electric hyperfine parameters (i.e. the isomer shift and the quadrupole splitting), as well as by sample-specific parameters, such as the thickness and texture (a parameter describing the possibility of preferential orientation of the molecules on the substrate). ${ }^{63}$

Appropriate fitting of the spectra required two further steps: (1) a distribution of quadrupole splitting values $\left(\Delta E_{\mathrm{Q}}\right)$, which was assumed to be Gaussian, with a standard deviation $\sigma$; and (2) a correlation between the quadrupole splitting and the isomer shift $(\delta)$, with

$$
\delta \quad \delta_{0}=\alpha \frac{\left(\Delta E_{\mathrm{Q}} \quad \Delta E_{\mathrm{Q}, 0}\right)}{2}
$$

where $\alpha$ is the correlation coefficient and $\delta_{0}$ and $\Delta E_{\mathrm{Q}, 0}$ are respectively the mean values of $\delta$ and $\Delta E_{\mathrm{Q}}$. Eqn (1) resulted in different linewidths of each line of the quadrupole doublet. 
For a proper comparison, the same fitting procedure was used also for the in house Mössbauer transmission measurements realized on the ${ }^{57} \mathbf{1}$ microcrystalline sample (see Fig. S2-S4 and Table $\mathrm{S} 1$ in the ESI $\dagger$ ).

\section{Results}

\section{Thermally induced SCO transition}

The temperature-dependent Mössbauer spectra of the two ${ }^{\mathbf{5 7}} \mathbf{1}$ ultrathin films are reported in Fig. 1. The $50 \mathrm{~nm}$ thick film spectrum at $240 \mathrm{~K}$ features as a main contribution a doublet with a quadrupole splitting of approximately $2 \mathrm{~mm} \mathrm{~s}^{-1}$, characteristic of the HS state of ${ }^{57} \mathbf{1}$ in the bulk phase. ${ }^{56}$ The spectrum is not symmetric, pointing to the presence of a minor LS contribution. Upon lowering the temperature, the $50 \mathrm{~nm}$ thick film spectra feature an overall broadening of the two main absorption lines and the increase in weight of a third line attributed to one line of the LS doublet, weakly evidenced also at high temperature and centred at $c a .0 .7 \mathrm{~mm} \mathrm{~s}^{-1}$. Finally, at $3.0 \mathrm{~K}$, a significant contribution from the HS state is still present, pointing here to an incomplete spin conversion.

In the $5 \mathrm{~nm}$ thick sample spectra (Fig. $1 \mathrm{~b}$ ), a low $\mathrm{S} / \mathrm{N}$ ratio is evident, as expected for the reduced number of ${ }^{57} \mathrm{Fe}$ nuclei present in this sample. Nevertheless, a clear evolution of the spectra with temperature is observable also in this sample, thus confirming the thermally induced SCO transition, even if in this case the HS contribution is significant in all the investigated temperature range, indicating only a partial conversion.
The synchrotron Mössbauer spectra of the ${ }^{\mathbf{5 7}} \mathbf{1}$ drop-cast sample recorded at high and low temperature are reported in Fig. 2. At $278 \mathrm{~K}$, the spectrum qualitatively resembles that measured at room temperature for the $50 \mathrm{~nm}$ thick film, except for the increased intensity of the spectral lines due to the higher number of ${ }^{57} \mathrm{Fe}$ nuclei present with respect to the sublimated sample. It again features an asymmetric doublet with a quadrupole splitting of approximately $2 \mathrm{~mm} \mathrm{~s}^{-1}$, characteristic of the HS state of ${ }^{57} \mathbf{1}$ in the bulk phase, ${ }^{56}$ with a minor LS contribution. At $3.0 \mathrm{~K}$, the doublet is broadened, and a third line appears at about $0.7 \mathrm{~mm} \mathrm{~s}^{-1}$, which can be ascribed to the quadrupole-split line of the LS state. Contrarily to ${ }^{57} \mathbf{1}$ in the bulk phase (see Fig. S2 and Table S1 in the ESI $\dagger$ ), the HS contribution to the Mössbauer spectrum at low temperature is not negligible, accounting for $60(1) \%$ (see Data analysis and discussion).

\section{LIESST effect}

The $50 \mathrm{~nm}$ and the $5 \mathrm{~nm}$ thick films were irradiated at low temperature ( $6.0 \mathrm{~K}$ and $3.0 \mathrm{~K}$, respectively) employing LEDs selected according to their wavelengths at low temperature and mounted on the sample holders in order to be able to irradiate in situ (see Experimental for details). Mössbauer spectra measured after various irradiation times (up to about 3 hours) are shown in Fig. 3 (for the $50 \mathrm{~nm}$ thick film three representative irradiation times are reported, while all spectra are reported in Fig. S13, ESI $\dagger$ ). For both samples, the temporal evolution of the shape of the spectra shows that a fraction of molecules is photoconverted from the LS state to the HS state, as confirmed by the fit of the spectra (see Data analysis and discussion).
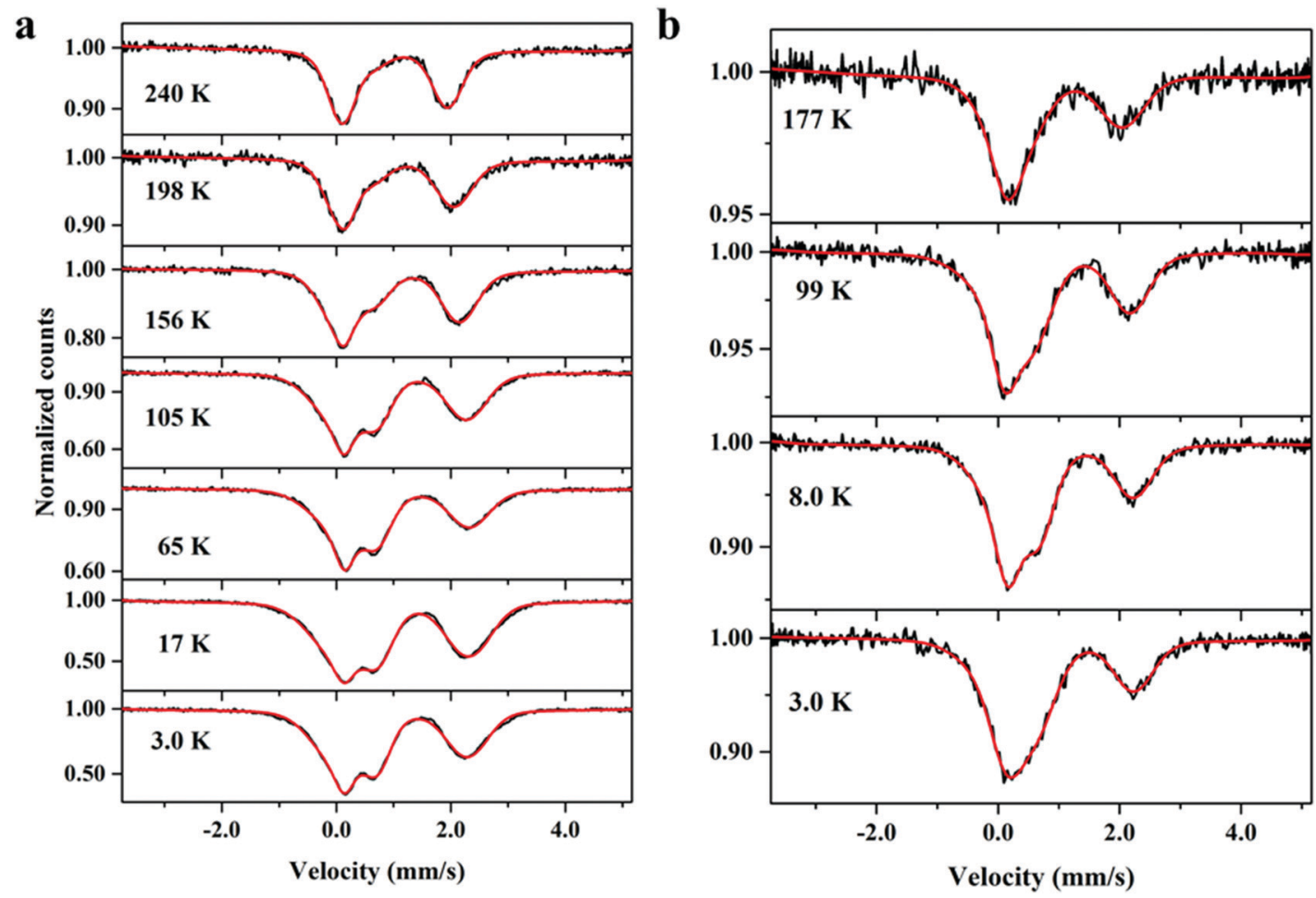

Fig. 1 Temperature dependence of the ${ }^{57} \mathrm{Fe}$ Mössbauer spectra for ${ }^{57} \mathbf{1}$ thin films. Experimental spectra (black lines) and best fit curves (red lines) for (a) $50 \mathrm{~nm}$ thickness and (b) $5 \mathrm{~nm}$ thickness. Residuals are reported in the ESI (Fig. S7 S10). 


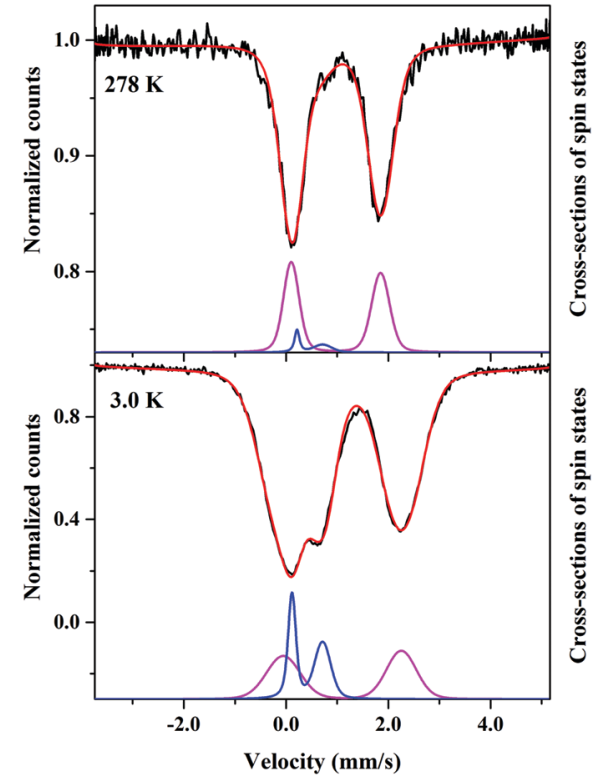

Fig. $2{ }^{57} \mathrm{Fe}$ Mössbauer spectra of the drop cast deposit of ${ }^{57} 1$. Experi mental spectra (black lines) and best fit curves (red lines). Residuals are reported in the ESI $\dagger$ (Fig. S11 and S12). The absorption cross sections associated with the HS state (magenta line) and the LS state (blue line) are shown.

\section{Data analysis and discussion}

\section{Thermally induced SCO transition}

Rather good agreement between the measured and calculated spectra is achieved over all the thermal range for the sublimated films (see Fig. 1) and the drop-cast sample (see Fig. 2). The contributions of the HS and LS components used in the fitting procedure at representative temperatures are reported in Fig. 2 for the drop-cast sample and Fig. 4 and Fig. S14 (ESI $\dagger$ ) for the $50 \mathrm{~nm}$ and $5 \mathrm{~nm}$ thick samples, respectively. The refined parameters extracted from the fit of the spectra acquired at the highest temperature and $3.0 \mathrm{~K}$ are reported in Table 1 , while the parameters extracted for each temperature are reported in Tables S5 and S7 in the ESI. $\dagger$

In the drop-cast sample and the sublimated films, the values of the hyperfine parameters for the HS state agree quite well with those obtained from the fit of the in house Mössbauer characterization of ${ }^{\mathbf{5 7}} \mathbf{1}$ (see Table S1, ESI $\dagger$ ). The parameters extracted from this last sample agree well with those reported previously in the literature for ${ }^{57} \mathbf{1}$ in the bulk phase. ${ }^{47,56}$ Moreover, for the drop-cast sample and the ultrathin films rather good agreement is found also for the quadrupole splitting of the LS state. For the LS isomer shift, a small but appreciable variation is found at low temperature, while there is agreement at high temperature at least for the $50 \mathrm{~nm}$ thick sample. Furthermore, the shape of the cross-section due to the HS state is made up of an approximatively symmetric doublet (low value of $\alpha$ ) and it broadens as the temperature decreases (while $\sigma$ increases).

On the contrary the LS contribution is clearly asymmetric and constituted of one narrow line with practically natural linewidth and a second line that is about ten times broader (see Fig. 1 and 4). This asymmetry in the absorption lines of each species is absent in the bulk sample (see Note S1, Fig. S2 and Table $\mathrm{S} 1$ in the ESI $\dagger$ ). Therefore, the clear appreciable
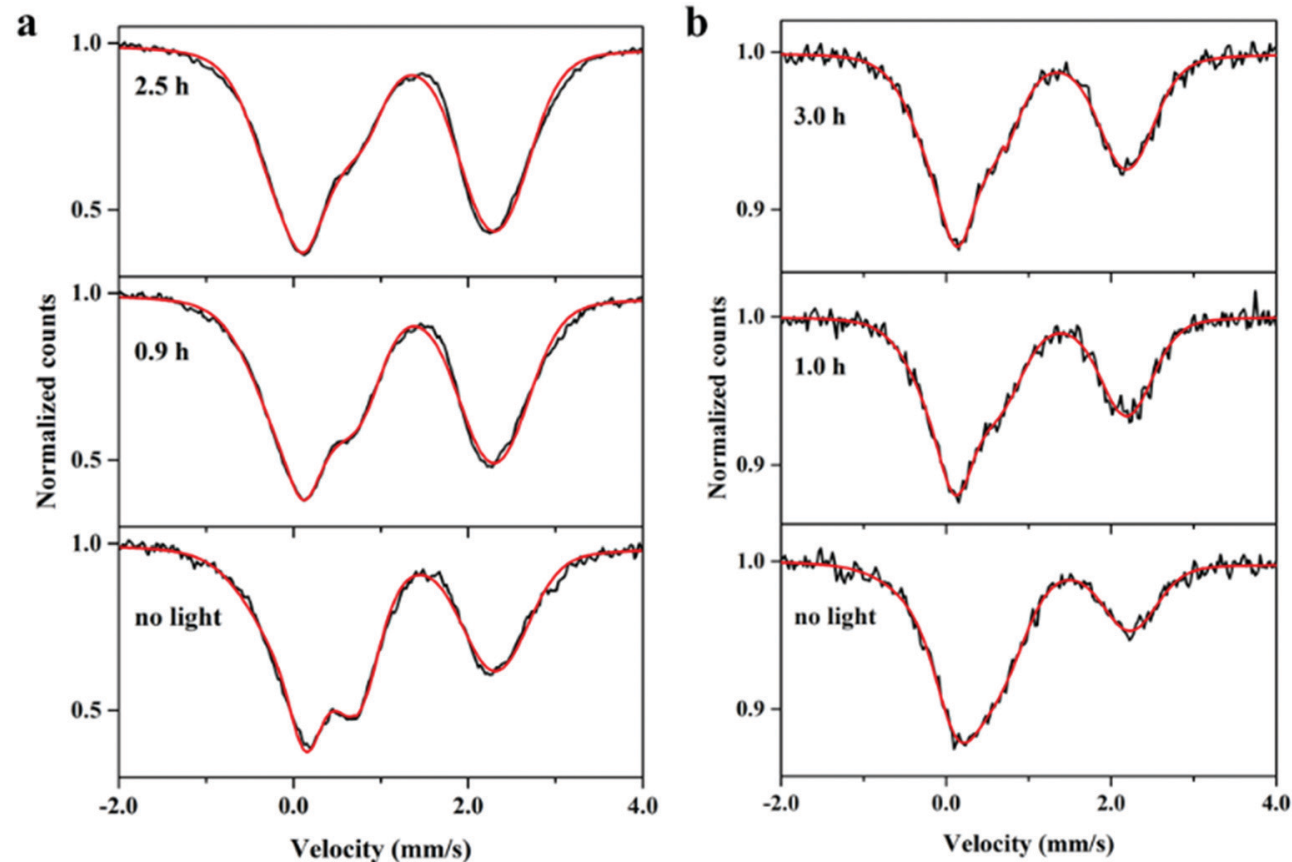

Fig. $3{ }^{57} \mathrm{Fe}$ Mössbauer spectra evolution with irradiation time (LIESST effect). Experimental spectra (black lines) and best fit curves (red lines) of the $50 \mathrm{~nm}$ thick film (a) and the $5 \mathrm{~nm}$ thick film (b). Best fit parameters are reported in Tables S9 and S12 (ESI + ), while HS/LS absorption cross sections and residuals are reported in Fig. S18 S21 (ESI $\dagger)$. The velocity range is restricted to better evidence the relevant part of the spectra. 


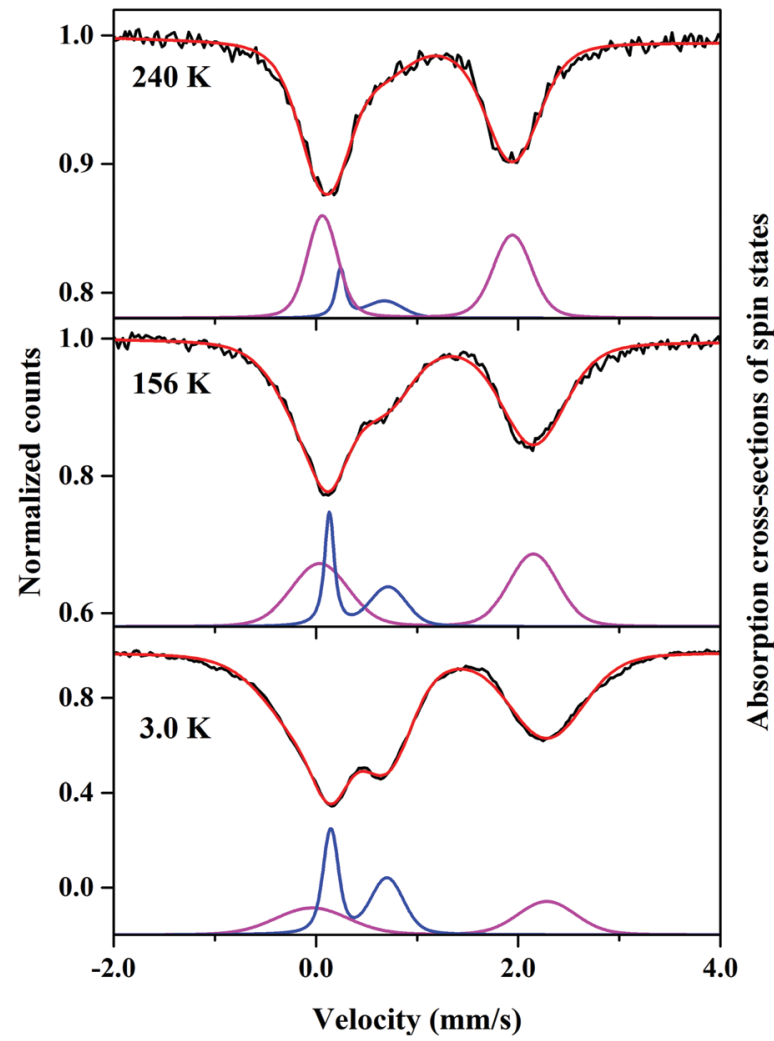

Fig. 4 Fitting of selected ${ }^{57} \mathrm{Fe}$ Mössbauer spectra of the ${ }^{57} 150 \mathrm{~nm}$ thick film. Experimental spectra (black lines) and best fit curves (red lines) for three selected temperatures. The absorption cross sections associated with the HS state (magenta line) and the LS state (blue line) are shown. The velocity range is restricted to better evidence the relevant part of the spectra.

Table $1{ }^{57} \mathrm{Fe}$ Mössbauer parameters of the HS and LS states extracted from the fit of the spectra measured at the highest and lowest temperature for each sample: isomer shift $\left(\delta_{0}\right)$ and quadrupole splitting $\left(\Delta E_{Q}\right)$ mean values and calculated HS fraction (\%HS). Parameters with no error were kept fixed in the fitting procedure

\begin{tabular}{|c|c|c|c|c|c|}
\hline Sample & $T(\mathrm{~K})$ & Spin state & $\delta_{0}{ }^{a}\left(\mathrm{~mm} \mathrm{~s}^{1}\right)$ & $\Delta E_{\mathrm{Q}, 0}\left(\mathrm{~mm} \mathrm{~s}^{1}\right)$ & $\% \mathrm{HS}$ \\
\hline \multirow[t]{4}{*}{ Drop cast } & \multirow[t]{2}{*}{278} & HS & $0.975(8)$ & $1.75(2)$ & \multirow[t]{2}{*}{$91(4)$} \\
\hline & & LS & $0.47(8)$ & $0.5(2)$ & \\
\hline & \multirow[t]{2}{*}{3.0} & HS & $1.101(1)$ & $2.311(2)$ & \multirow[t]{2}{*}{$60(1)$} \\
\hline & & LS & 0.41 & 0.6 & \\
\hline \multirow[t]{4}{*}{$50 \mathrm{~nm}$} & \multirow[t]{2}{*}{240} & HS & $1.003(4)$ & $1.880(8)$ & \multirow[t]{2}{*}{$84(3)$} \\
\hline & & LS & $0.46(2)$ & $0.44(3)$ & \\
\hline & \multirow[t]{2}{*}{3.0} & HS & $1.122(2)$ & $2.324(5)$ & \multirow[t]{2}{*}{$50(1)$} \\
\hline & & LS & $0.425(2)$ & $0.558(3)$ & \\
\hline \multirow[t]{4}{*}{$5 \mathrm{~nm}$} & \multirow[t]{2}{*}{177} & HS & $1.11(7)$ & $1.9(1)$ & \multirow[t]{2}{*}{$58(8)$} \\
\hline & & LS & $0.26(7)$ & $0.2(2)$ & \\
\hline & \multirow[t]{2}{*}{3.0} & HS & $1.12(4)$ & $2.22(7)$ & \multirow{2}{*}{$41(4)$} \\
\hline & & LS & $0.26(7)$ & $0.2(2)$ & \\
\hline
\end{tabular}

difference in the Mössbauer parameters between those of the bulk sample and the surface deposited samples is the LS isomer shift and the correlation between the broadening of the hyperfine parameters both for the HS and LS state.
Further details concerning the electronic structure of the molecules in the different samples can be extracted from the thermal behaviour of the hyperfine parameters of the HS and LS states (Fig. 5). For the LS state, the isomer shift of the $50 \mathrm{~nm}$ thick sample is less dependent on the temperature with respect to the bulk phase, in which a temperature dependence analogous to that of the HS state is observed. Therefore, in the LS state of the sublimated sample, a mechanism compensating the second order Doppler effect should be active, resulting in an isomer shift which is practically temperature independent. This effect could be related to a dependence of the molecular wavefunction on the temperature which could be induced by the substrate. For the $5 \mathrm{~nm}$ thick sample (see Fig. 5), the thermal behaviour of the LS isomer shift seems more abrupt with respect to the bulk and the other deposited samples. Although we lack a clear explanation for this difference, we suppose it to be related to an even more pronounced role of the surface in this last sample.

Moreover, one can notice that the values of the hyperfine parameters of the HS state increase upon lowering the temperature. In particular, the isomer shift exhibits the usual temperature dependence ${ }^{63}$ due to the second order Doppler effect, showing a linear dependence on the logarithm of the total effective thickness $\left(t_{\mathrm{a}}\right)$ with a slope of $0.05(1) \mathrm{mm} \mathrm{s}^{-1}$ for the $50 \mathrm{~nm}$ thick sample $\left(\delta v s . \ln \left(t_{\mathrm{a}}\right)\right.$, as reported in Fig. 6). This trend is in good agreement with a theoretical model reported previously, ${ }^{63}$ considering that the slope value depends on the actual dispersion of phonon modes and on the ratio between the $f$ value of the HS and LS states. A different behaviour is observed for the HS state of the $5 \mathrm{~nm}$ thick sample, for which $\delta v s . \ln \left(t_{\mathrm{a}}\right)$ remains constant (see Fig. 6), again possibly pointing to a more pronounced role of the surface in this last sample. However, the $\delta v s . \ln \left(t_{\mathrm{a}}\right)$ behaviour of the LS state is opposite to that of the HS state (see Fig. 6) and their interpretation is not straightforward.

By fitting the temperature dependence of the effective thickness of the samples by means of the Debye model (see Fig. S15, ESI $\dagger$ ), Debye temperatures of 106(8) K and 128(2) K were found for the $50 \mathrm{~nm}$ and $5 \mathrm{~nm}$ thick films, respectively. These values are of the same order of magnitude and are in line with values reported beforehand for the bulk sample. ${ }^{47}$ However, the difference between the Debye temperatures of the two samples together with the different trend of $\delta v s . \ln \left(t_{\mathrm{a}}\right)$ may suggest that the vibrational properties of the molecules depend on the thickness of the sublimated molecules.

Most importantly, considering the thermal behaviour of both the $50 \mathrm{~nm}$ sublimated film and of the drop-cast sample, a ratio of the effective thicknesses equal to 2.7 was obtained. This would point towards a nominal thickness for the latter of the order of $140 \mathrm{~nm}$. Although this is just a rough estimation, due to the uncontrolled smoothness and coverage for the dropcast sample and a certain inhomogeneity of the deposit, it explains the similar behaviour of the two samples, and the observed difference with respect to the bulk. The low thickness of the drop-cast sample may derive from the low solubility of ${ }^{57} \mathbf{1}$ in dichloromethane used for this experiment. 

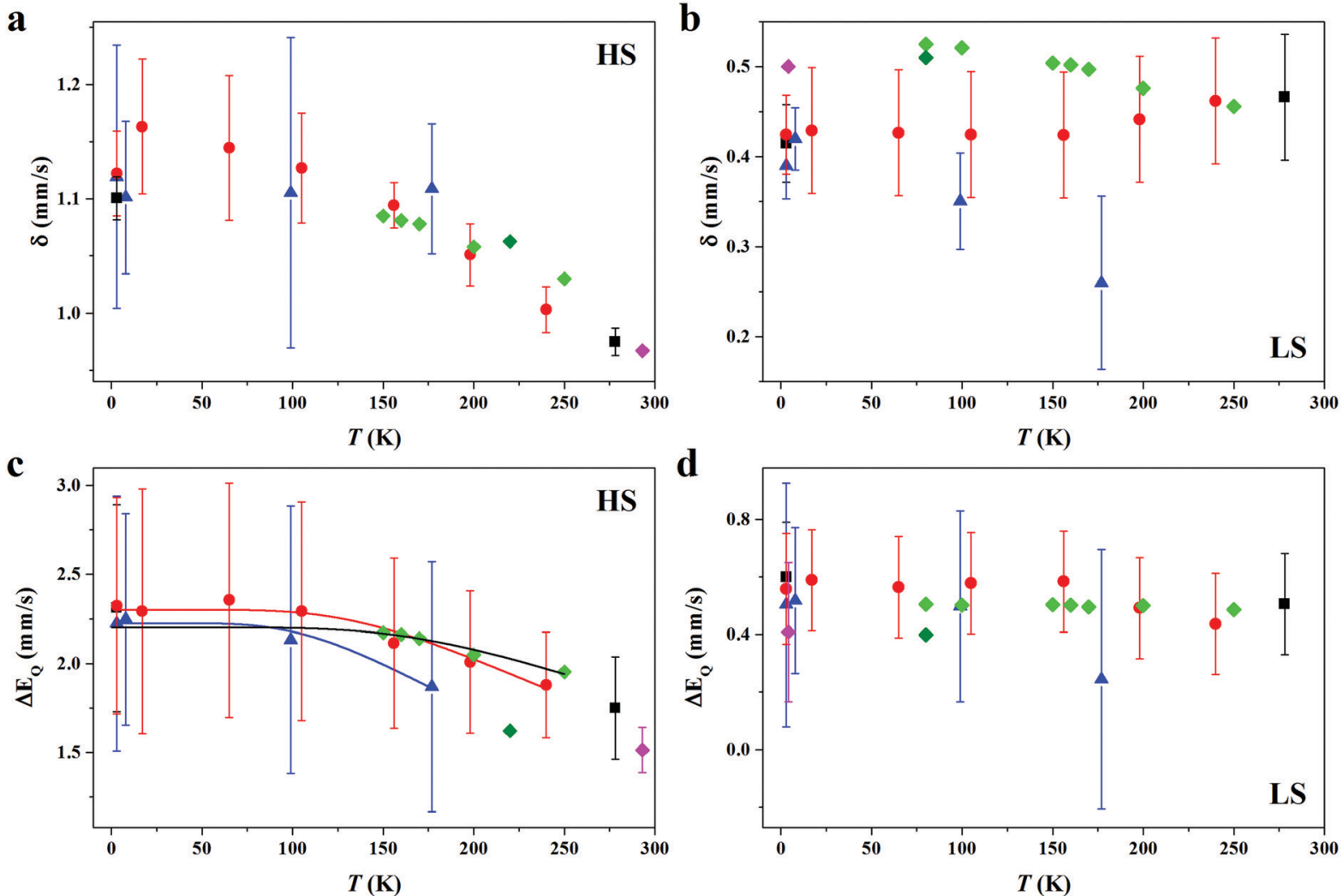

Fig. 5 Temperature dependence of the mean value of ${ }^{57} \mathrm{Fe}$ Mössbauer hyperfine parameters. The $50 \mathrm{~nm}$ (red dots) and the $5 \mathrm{~nm}$ (blue triangles) thick film, the drop cast sample (black squares) and the microcrystalline sample (magenta diamonds) isomer shifts with respect to $\alpha$ Fe (panel (a) HS state, panel (b) LS state) and quadrupole splittings (panel (c) HS state, panel (d) LS state). The distributions are reported as bars around the mean value, except for the isomer shift of the microcrystalline sample for which the mean value with its error bar is reported. In panel (c), fits corresponding to the sublimated samples and bulk with eqn (2) are shown. All values are reported in the ESI† (Tables S5 and S7). Light and dark green diamonds are data for the bulk extracted from ref. 56 and 47, respectively.

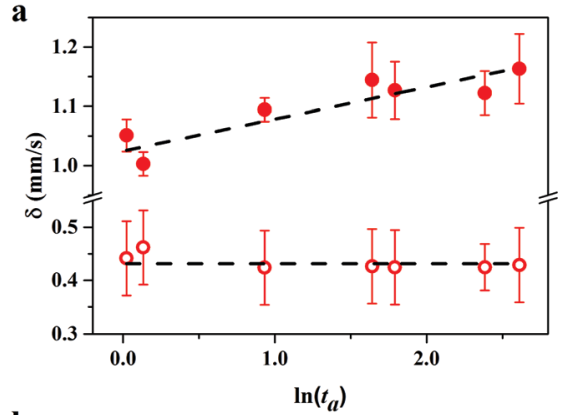

$\mathbf{b}$

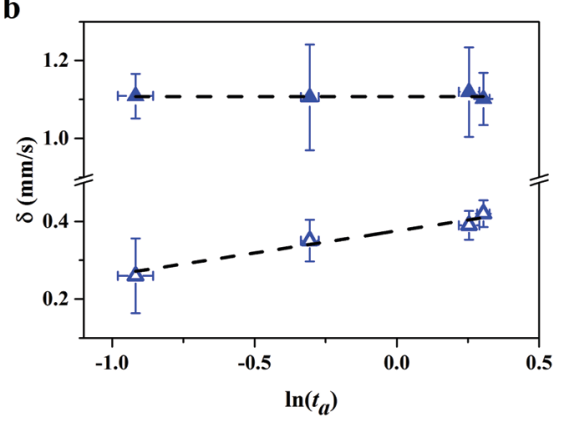

Fig. 6 HS (filled symbols) and LS (open symbols) isomer shift of the $50 \mathrm{~nm}$ (a) and $5 \mathrm{~nm}$ (b) thick films as a function of the total effective thickness. The dashed lines are linear fits.
The temperature dependence of the Fe(II) quadrupole splitting of the HS state can be fitted by the relation

$$
\Delta E_{\mathrm{Q}, 0}=A \frac{1 \exp (\Delta / T)}{1+2 \exp (\Delta / T)}
$$

where $\Delta$ is the energy splitting between the energy levels of the $\mathrm{t}_{2 \mathrm{~g}}$ state considering a Jahn-Teller distortion of the regular octahedron, $A$ is a parameter related to the energy level splitting in the crystalline field, and $T$ is the temperature. Fits of the HS state quadrupole splitting values with eqn (2) are shown in Fig. 5c. They give $A=2.30(3) \mathrm{mm} \mathrm{s}^{-1}$ and $\Delta=627(21) \mathrm{K}(54(2) \mathrm{meV})$ and $A=2.22(2) \mathrm{mm} \mathrm{s}^{-1}$ and $\Delta=494(23) \mathrm{K}(43(2) \mathrm{meV}$ ) for the $50 \mathrm{~nm}$ and $5 \mathrm{~nm}$ thick samples, respectively. Therefore a $20-40 \%$ reduction in the $\Delta$ value is observed when the ${ }^{57} \mathbf{1}$ molecules are deposited on a substrate ( $50 \mathrm{~nm}$ and $5 \mathrm{~nm}$ ) with respect to molecules in the bulk phase, for which values of $A=2.20(2) \mathrm{mm} \mathrm{s}^{-1}$ and $\Delta=787(29) \mathrm{K}$ (69(2) meV) can be extracted from a fit with eqn (2) of data reported in ref. 56 (see Fig. 5c). Here, the crystal field parameters extracted from the Mössbauer spectra point towards geometrical constraints induced by the packing of the molecules on the surface. The subtlety of these effects, combined with the lack of structural data at the nanoscale, prevents any straightforward indication of the nature of the geometrical deformations imposed on the molecules. 
The observed distributions of the quadrupole splitting values are instructive data since they can be related to heterogeneity in the Fe-ligand distances of the ${ }^{\mathbf{5 7}} \mathbf{1}$ molecules in the sublimated films. In fact, by taking the value of $\sigma$ extracted from the fit of the Mössbauer spectra as an uncertainty in the electric quadrupole splitting and recalling the radial dependence of this splitting, the Fe-ligand distribution can be evaluated. From the experimental distribution of quadrupole splitting of the HS state, we can estimate at $3.0 \mathrm{~K}$ a distribution of the order of $0.04 \AA$ of the Fe-ligand distances for all three samples, while for the LS state such a distribution is of the order of $0.01 \AA$ in all the thermal range for the three samples. ${ }^{63}$ Notably, these distributions of the Fe-ligand distances are almost one order of magnitude lower than the general accepted changes in the Fe-ligand distances associated with the transition between HS and LS states in the bulk phase. ${ }^{46}$ Moreover, these values are confirmed by the $\mathrm{Fe}-\mathrm{N}$ distances obtained by X-ray diffraction structures of $\mathbf{1}$ in the LS and HS states (see Fig. S16 and Note $\mathrm{S} 2$ in the ESI $\dagger){ }^{55}$ Therefore, the correlation found between the hyperfine parameters of the spectra of the sublimated samples is likely to be induced by the interaction with the surface and would indicate a heterogeneity of the crystal field that allows a partial delocalization of electron density on the $e_{g}$ levels, which ultimately influences the switching properties. Moreover, considering that no preferential orientation of the molecules in the sublimated samples was evident from the data analysis, we tentatively reach the conclusion that the differences seen between the sublimated/drop-cast samples and the bulk appear thus to be exclusively attributable to changes in the electronic structure induced by the surface.

To further analyse the quadrupole splitting, Density Functional Theory (DFT) calculations were performed on 1, which allowed us to evaluate the Electric Field Gradient (EFG) tensor according to the protocol reported in the literature, ${ }^{64}$ which yielded excellent results for closely related Fe(II) pyrazolyl-borate complexes (see Note S3 in the ESI $\dagger$ for details). The DFT calculations show a quite high sensitivity of the EFG to the constraints on the geometry of the phen and $\mathrm{H}_{2} \mathrm{Bpz}_{2}$ ligands, supporting the assertion that the distribution of quadrupole splitting observed is another direct consequence of the interaction of the complexes with the surface and the resulting geometrical deformation incurred.

Finally, concerning the spin conversion of the investigated samples, the high spin fractions (\%HS), calculated from HS and LS absorption cross-sections, as a function of temperature are reported for all samples in Fig. 7. For the $50 \mathrm{~nm}$ thick film, the HS fraction at $240 \mathrm{~K}$ and $3.0 \mathrm{~K}$ amounts to $84(3) \%$ and $50(1) \%$, respectively. The reduced efficiency of the SCO with respect to molecules in the microcrystalline material can be ascribed to an effect of the interaction between the molecules and the substrate or to a distortion of the molecules with respect to the regular structure assumed in the crystals. These effects may be responsible for another observed behaviour of the sample: the gradual spin transition of the $50 \mathrm{~nm}$ thick sample. This slower transition than in the bulk phase may still be compatible with a cooperative phenomenon, ${ }^{1}$ although most likely hampered by the heterogeneity of the sample (distribution of the Fe-ligand distances) induced by the molecule-substrate interaction.

In the temperature range between $3.0 \mathrm{~K}$ and $177 \mathrm{~K}$, about $20 \%$ of the molecules of the $5 \mathrm{~nm}$ thick film undergo SCO. At high temperatures, the characterization of this sample is more difficult due to the decrease of the $\mathrm{S} / \mathrm{N}$ ratio of the spectra, which results in increased uncertainty in the extracted parameters. Although a clear comparison between the data relative to the $50 \mathrm{~nm}$ and $5 \mathrm{~nm}$ samples is not possible, the trend of $\% \mathrm{HS}$ for the $5 \mathrm{~nm}$ thick film seems to indicate a decreased spin conversion. This in turn could be related to the different vibrational properties for the $5 \mathrm{~nm}$ thick sample with respect to the $50 \mathrm{~nm}$ thick one, as suggested previously by the analysis of the hyperfine parameters.
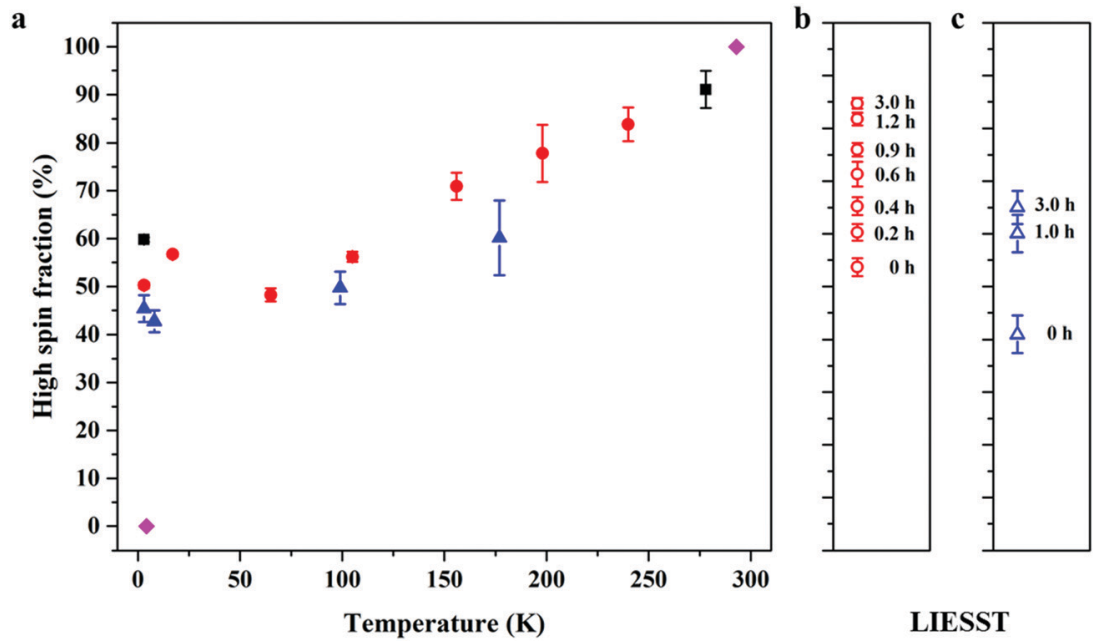

Fig. $7 \mathrm{HS}$ fraction evolution with temperature and light irradiation. (a) \%HS vs. temperature for the $50 \mathrm{~nm}$ thick film (red dots), the $5 \mathrm{~nm}$ thick film (blue triangles), the drop cast sample (black squares) and the microcrystalline sample (magenta diamonds). (b) \%HS evolution with time for the $50 \mathrm{~nm}$ thick film under light irradiation at $6.0 \mathrm{~K}$. (c) \%HS evolution with time for the $5 \mathrm{~nm}$ thick film under light irradiation at $3.0 \mathrm{~K}$. 
For the drop-cast sample, at high temperature, a minor contribution of the LS state is present, in agreement with measurements realized on the microcrystalline sample of ${ }^{57} 1$ (see Fig. S2 and Table S1, ESI, $\dagger$ and ref. 47 and 56). At $3.0 \mathrm{~K}$ there is still a very high contribution $(\sim 60 \%)$ of the HS state, in line with the estimated thickness.

Overall a partial spin conversion is detected by SMS spectroscopy for the three thin samples: both sublimated and the drop-cast samples. Consequently, we suggest that, for ${ }^{57} \mathbf{1}$ on a gold substrate, the effect of the molecule-surface interaction "propagates" from a few layers up to 50-100 nm of sublimated molecules, as evidenced by the changes of the parameters obtained by the analysis of the Mössbauer data $(\Delta, \mathrm{Fe}-\mathrm{N}$ distance distribution, $\delta$ vs. $\ln \left(t_{\mathrm{a}}\right)$, and the more gradual SCO conversion, to recall a few of them). Our interpretation, which surely will need to be further supported by other experimental evidence, is surprising for this class of SCO complexes, since previous experiments tended to indicate that effects of the surface would vanish over a few layers. ${ }^{24,26,40,59,60,65-68}$ Moreover, thanks to the high resolution and sensitivity of SMS spectroscopy, we can correlate the decreased spin conversion with the observed fine structural differences between the sublimated samples and the bulk phase. This hypothesis is in line with a recent report by Tuczek et al. ${ }^{69}$ that associated the presence of polymorphism to an alteration of cooperativity effects that are at the basis of the spin transition behaviour. However, although parameters extracted from the analysis, such as the decrease of $\Delta$ and the change in slope of $\delta v s \cdot \ln \left(t_{\mathrm{a}}\right)$, appear to be relevant, the variations observed need an accurate interpretation that goes beyond the focus of the present work.

\section{LIESST effect}

As a final point of our discussion, the photoactivity of the ${ }^{57} \mathbf{1}$ thin films is addressed. A rather good agreement between measured and calculated spectra is achieved for both sublimated samples (see Fig. 3). Interestingly, the broadening of the distribution of the isomer shift values of the HS state (see Fig. S22, ESI $\dagger$ ) decreases with the irradiation time, indicating that irradiation is more selective in populating excited spin states with respect to thermal excitation. Moreover, the mean values of the hyperfine parameters after 2.5 hours of irradiation show slight changes with respect to the initial ones. These variations may be linked to what observed by Bernien et $a l^{28} \mathbf{1}$ for ultrathin films of $\mathbf{1}$ on graphite, where they studied $\mathbf{1}$ by means of X-ray absorption spectroscopy (XAS). The Fe $\mathrm{L}_{2,3}$ XAS spectra recorded at room temperature (HS) and after laser irradiation at $6 \mathrm{~K}$ (induced HS) slightly differ in the pre-edge region. A possible explanation for those differences was reported to be related to the different thermal population of HS states closely spaced in energy and this was confirmed by multiplet calculations. ${ }^{28} \mathrm{~A}$ simpler and likelier explanation is related to what is known for $\left[\mathrm{Fe}\left(\mathrm{H}_{2} \mathrm{~B}(\mathrm{pz})_{2}\right)_{2}\right.$ phen]: irradiation with $633 \mathrm{~nm}$ light at $30 \mathrm{~K}$ produces a HS state with the triclinic symmetry of the starting LS state, and thus a different molecular structure and crystal packing from the monoclinic high temperature HS state. ${ }^{55}$
The calculated \%HS is reported in Fig. 7 for both sublimated samples. The increase of the HS component is quick in the first hour of irradiation (see Fig. S23, ESI $\dagger$ ), but appears to saturate for longer irradiation times. After 2.5 hours of irradiation, the SCO efficiency induced by the LIESST effect in the $50 \mathrm{~nm}$ thick sample is about $30 \%$, comparable with the value due to the thermal excitation. The same consideration holds for the $5 \mathrm{~nm}$ thick sample: after 3.0 hours of irradiation, it amounts to about $25 \%$, within the error of that thermally induced.

\section{Conclusions}

The SCO efficiency of ${ }^{57} \mathbf{1}$ deposited as thin films on gold substrates was investigated by means of SMS spectroscopy in the energy-domain. This is to the best of our knowledge the first study reported in the literature exploiting this technique for the characterization of nanostructured SCO systems, demonstrating thus its feasibility. The selected SCO system was studied both by varying the temperature and by light irradiation of the samples. Both experiments show that, once deposited on a gold substrate, the efficiency of the SCO mechanism is modified. The SCO conversion between $278 \mathrm{~K}$ and $3.0 \mathrm{~K}$ for the drop-cast sample and the $50 \mathrm{~nm}$ sublimated one amounts to about $30 \%$. Due to low $\mathrm{S} / \mathrm{N}$ ratios, the Mössbauer data for the $5 \mathrm{~nm}$ thick sample are limited to the $177-3.0 \mathrm{~K}$ range, in which a $20 \%$ spin conversion is achieved. Moreover, conversion efficiencies comparable to those thermally induced were obtained by the LIESST effect.

Overall only a partial spin conversion is detected by SMS spectroscopy for the three thin samples we investigated. Consequently, we suggest that for ${ }^{\mathbf{5 7}} \mathbf{1}$ the used deposition protocols affect the molecular behaviour probably because of differences in the molecular packing, which could be reflected in the Mössbauer spectra and therefore related to the evidenced changes of the parameters obtained by the analysis of the Mössbauer data $\left(\Delta\right.$, Fe-N distance distribution, $\delta$ vs. $\ln \left(t_{\mathrm{a}}\right)$, and the more gradual SCO conversion). This is in line with recent experiments performed on similar complexes using a multiple-characterization technique approach on thicker samples (several hundreds of nanometers). ${ }^{69}$

In conclusion, the high resolution and sensitivity of this technique reveal relevant and fine changes in the Fe-based SCO electronic structure once deposited on a surface. Our interpretation, which surely will need to be confirmed in the future by other experimental and theoretical investigations, is surprising for this class of SCO complexes, since previous experiments tended to indicate that effects of the surface would vanish over a few layers, ${ }^{24,26,40,59,60,65-68}$ while the evidence we provide here suggests a more detrimental and long range effect due to the substrate.

\section{Experimental}

\section{Synthesis}

A ${ }^{57}$ Fe strip (99\% isotopically enriched, $21.85 \mathrm{mg}, 0.384 \mathrm{mmol}$ ) was reacted in a Schlenck tube under argon with an ethanolic 
solution of $\mathrm{HCl}$ (Sigma-Aldrich, 1.25 M, $5 \mathrm{~mL}$ ). After 4 days, further $\mathrm{HCl}$ was added $(3 \mathrm{~mL})$ and the solution sonicated. Complete dissolution was obtained after 11 days. The resulting pale-green solution was dried under a vacuum to remove the excess hydrogen chloride. Upon dissolution in freshly distilled dry deoxygenated methanol (3 mL), addition of a $\mathrm{MeOH}$ solution ( $3 \mathrm{~mL}$ ) of $\mathrm{KH}_{2} \mathrm{Bpz}_{2}$ (TCI, $143 \mathrm{mg}, 0.769 \mathrm{mmol}$ ) yielded a colorless solution of $\left[\mathrm{Fe}\left(\mathrm{H}_{2} \mathrm{Bpz}_{2}\right)_{2}\right]$. After filtration under argon to remove the $\mathrm{KCl}$ by-product, this solution was layered over a dichloromethane solution $(1 \mathrm{~mL})$ of 9,10-phenantroline (Acros, $69 \mathrm{mg}, 383 \mathrm{mmol}$ ) with an intermediate buffer of dichloromethane/methanol $(1: 1,2 \mathrm{~mL})$. The Schlenck tube was covered with aluminum paper to avoid direct light, which was seen to cause gas evolution. Violet well-shaped mm-sized prismatic crystals of ${ }^{57} 1$ were obtained after 6 days (60 mg, 34\% yield) and washed with ice-cold methanol and diethylether. $\mathrm{X}$-ray diffraction of one crystal confirmed the identity of the crystal cell as the one reported in the literature. The whole procedure was rehearsed multiple times starting from nonenriched Fe powder to ascertain that the correct product could be obtained reliably.

\section{Magnetometry and Raman spectroscopy}

Magnetic measurements were performed on a Quantum Design MPMS-5XL SQUID magnetometer. Samples were weighed on a Mettler-Toledo MX5 microbalance, then sealed in small bags made of 30 micrometer-thick polyethylene. Measurements were performed under a $2 \mathrm{~T}$ magnetic field.

Raman spectrum measurements were performed with a Jobin-Yvon LabRAM HR800 high spectral resolution spectrometer between 0 and $2000 \mathrm{~cm}^{-1}$. A 1200 groove $\mathrm{cm}^{-1}$ grating was used for the Raman spectral dispersion after excitation with a green Coherent Sapphire 532-50 SF CW solid state laser source (up to $50 \mathrm{~mW}, \lambda=531.97 \mathrm{~nm}$, TEM 00, single mode). A $100 \times$ NA 0.9 Olympus objective was used for laser excitation and visible light epi-collection. The laser power was adjusted to avoid damaging the molecular material: the laser power was limited to $10 \mathrm{~mW}$, further attenuated by a $50 \%$ filter. The power measured out of the objective was under these conditions about $100 \mu \mathrm{W}$.

\section{Sample deposition}

The evaporations were performed in a Plassys thermal evaporator connected to a glove box system. An alumina crucible was filled with the powder of ${ }^{57} \mathbf{1}$ and once the pressure reached the $10^{-7}$ mbar range the temperature was gently raised up to the evaporation temperature. The evaporation rate was followed by a quartz microbalance, and was stabilized in the $0.05 \mathrm{~nm} \mathrm{~s}^{-1}$ range at a temperature of $380-385 \mathrm{~K}$. The tooling factor was determined by our previous evaporation of a thick film of 1 on an ultra-flat silicon wafer through a soft porous PDMS membrane, and by checking the thickness of that film ex situ by AFM. $^{70}$ The substrate used was a thick polycrystalline gold film evaporated on silicon with a $5 \mathrm{~nm}$ Ti decoupling layer (SSENS, Enschede, NL).

\section{Mössbauer experiments}

Freshly synthesized ${ }^{57} \mathbf{1}$ was encapsulated in Mylar and ${ }^{57} \mathrm{Fe}$ transmission Mössbauer spectra were recorded in transmission geometry using a constant acceleration Halder-type spectrometer with a room temperature ${ }^{57}$ Co source (embedded in a Rh matrix). The velocity scale was calibrated according to the ${ }^{57} \mathrm{Fe}$ Mössbauer spectrum of pure $\alpha-\mathrm{Fe} 0$ foil recorded at room temperature. A helium bath cryostat suitable for Mössbauer experiments was used in order to record spectra from room temperature down to $4.2 \mathrm{~K}$.

Mössbauer spectra of the thin films were measured at ID18, the Nuclear Resonance Beamline ${ }^{31}$ of the European Synchrotron Radiation Facility (ESRF), taking advantage of the Synchrotron Mössbauer Source (SMS). ${ }^{61,62}$ As an acceptable compromise between linewidth and acquisition time, for the present measurements the full width at half maximum (FWHM) of the ${ }^{57} \mathrm{Fe}-$ resonant line was set at a value approximately three times larger than for a radioactive source (FWHM mean value $\sim 0.34 \mathrm{~mm} \mathrm{~s}^{-1}$ ), obtaining an intensity of about $1.5 \times 10^{4}$ photons per second. Before and after each Mössbauer measurement of the samples, transmission spectra of a single-line absorber $\left(\mathrm{K}_{2} \mathrm{Mg}^{57} \mathrm{Fe}(\mathrm{CN})_{6}\right)$ of known thickness were taken in order to evaluate and check the current FWHM value. From these single-line spectra the isomer shift of the SMS line was evaluated to be $0.709 \mathrm{~mm} \mathrm{~s}^{-1}$ with respect to conventional $\alpha$-Fe. The Mössbauer spectra of the samples were recorded by collecting the radiation reflected by the surface in a grazing incidence geometry. For each sample the incidence angle $\theta$ was chosen after measuring the reflectivity of the sample as a function of the angle: $\theta \sim 0.1^{\circ}$ for the drop-cast sample and between $0.1^{\circ}$ and $0.2^{\circ}$ for the sublimated samples. The spot size was $c a .18 \mu \mathrm{m}$ in both dimensions. Spectra were measured at different temperatures in the range 3.0-278 K using a superconducting He-exchange gas cryo-magnetic system. For the LIESST measurements the sample holder was modified in order to accommodate a couple of InGaAsP LEDs (Roithner LaserTechnik GmbH, nominal optical power $=2 \mathrm{~mW}$, see Fig. S24, ESI $\dagger$ ) with $1050 \mathrm{~nm}$ nominal wavelength, decreasing to $986 \mathrm{~nm}$ at $10 \mathrm{~K}$. The contribution of Fe impurities in the beryllium collimating lenses of the beamline, as detected in an "empty-can" Mössbauer spectrum (see Fig. S25, ESI $\dagger$ ), i.e. with no mounted sample, was subtracted from the experimental spectra.

\section{Fitting method}

The Mössbauer spectra realized with the SMS were interpreted by means of a fitting procedure based on the evaluation of the transmission integral function, which takes into account the dependence of the Mössbauer spectra on the sample effective thickness. The complete expression used to fit the spectra was

$$
Y(v)=N_{\mathrm{b}}(v)\left\{1 \quad \int_{-\infty}^{\infty} L_{2}^{\mathrm{S}}\left(\omega \quad v, \Gamma_{\mathrm{S}}\right)\left[1 \quad \exp \left(t_{\mathrm{a}}^{\mathrm{SMS}} \sigma(\omega)\right)\right] \mathrm{d} \omega\right\}
$$

where $Y(v)$ and $N_{\mathrm{b}}(v)$ are the detected counts and the spectrum baseline, respectively, as a function of the transducer velocity $v^{63}$ Moreover, $L_{2}^{\mathrm{S}}\left(\omega \quad v, \Gamma_{\mathrm{S}}\right)$ is the squared Lorentzian 
distribution (having $v$ and $\Gamma_{\mathrm{S}}$ as the center and FWHM, respectively) ${ }^{62}$ used to describe the source line shape. Finally, $\sigma(\omega)$ is the absorption cross-section of the sample as a function of the energy expressed in $\mathrm{mm} \mathrm{s}^{-1}(\omega)$ and $t_{\mathrm{a}}^{\mathrm{SMS}}$ is the effective thickness of the sample in the grazing incidence geometry.

The absorption cross-section of the samples was considered as the superposition of two contributions associated with an HS and an LS state and characterized by different distributions of hyperfine parameters (isomer shift $\delta$ and quadrupole splitting $\left.\Delta E_{\mathrm{Q}}\right)$. For the sake of simplicity symmetric distributions of the LS and HS quadrupole splitting, described by Gaussian functions centred on $\Delta E_{\mathrm{Q}, 0}$ of suitable standard deviations $\sigma$, were supposed. However, to interpret the asymmetry of the spectra, analogous Gaussian distributions of isomer shift values correlated to the previous ones by a correlation coefficient $\alpha$ were introduced. Correspondingly, two different distributions were associated with the hyperfine parameters $\delta$ and $\Delta E_{\mathrm{Q}}$ with the corresponding standard deviations calculated as $|\alpha \sigma|$ and $2 \sigma$, respectively. The result of this procedure is that the lines of each spin doublet are differently broadened, according to Gaussian functions characterized by standard deviations defined as $|\alpha \pm 1| \sigma$.

The effective thickness of the sample in the SMS setup is related to the sample effective thickness in a conventional Mössbauer setup by the factor $2 / \sin \theta$ (where $\theta$ is the grazing angle between the surface of the sample and the direction of the incoming radiation). The correctness of the fitting procedure was checked by finding a scaling factor of ten between the values of the thicknesses of the two sublimated samples.

Rather good agreement between the experimental and best fit data was found in the whole temperature range for all samples. For the drop-cast sample the $\chi^{2}$ values are 351 and 1022 for the 512 points, while for the $50 \mathrm{~nm}$ thick sublimated sample the $\chi^{2}$ values fall between 325 and 1272; despite the low $\mathrm{S} / \mathrm{N}$ ratio, especially at high temperatures, similar values are found for the $5 \mathrm{~nm}$ thick sublimated sample too (the $\chi^{2}$ values fall between 292 and 396 for the 512 points). Comparable agreement between the experimental and best fit data was found also for the spectra collected for different irradiation times (the $\chi^{2}$ values for the $50 \mathrm{~nm}$ and $5 \mathrm{~nm}$ thick samples fall between 499 and 1947 and 252 and 396, respectively, for the 512 points).

The Mössbauer spectra measured for the microcrystalline sample with a standard setup were fitted by evaluating the transmission integral function, having the same shape as eqn (3), except for the substitution of $L_{2}^{\mathrm{S}}$ by the Lorentzian line shape of the radioactive source and $t_{\mathrm{a}}^{\mathrm{SMS}}$ by the sample effective thickness in a conventional Mössbauer setup. Rather good agreement between the experimental and best fit data was found both at $293 \mathrm{~K}$ and $4.2 \mathrm{~K}$, with $\chi^{2}$ values of 1844 and 725 for the 256 points, respectively.

\section{Conflicts of interest}

There are no conflicts to declare.

\section{Acknowledgements}

The SMS experiments were performed on beamline ID18 at the European Synchrotron Radiation Facility (ESRF), Grenoble, France, and during $\mathrm{CH} 4909$ beamtime. We are grateful to Jean-Philippe Celse at the ESRF for providing assistance in using beamline ID18. This work was supported by Fondazione CR Firenze (2016.1104 grant for MF), the French National Research Agency (ANR) Investment for the Future Programme IdEx Bordeaux (ANR-10-IDEX-03-02, grants for MG and LP), FEMTOMAT project (ANR-13-BS04-002, PR) and the Italian MIUR ("Progetto Dipartimenti di Eccellenza 20182022, ref. B96C1700020008” allocated to Department of Chemistry “Ugo Schiff”). Gilles Pecastaings, LCPO, CNRS-University of Bordeaux, for help with the preparation of the thin films is gratefully acknowledged. Computer time for this study was provided by the computing facilities MCIA (Mésocentre de Calcul Intensif Aquitain) of the Universite de Bordeaux and of the Université de Pau et des Pays de l'Adour.

\section{References}

1 P. Gütlich and H. A. Goodwin. Spin crossover - an overall perspective, Spin Crossover in Transition Metal Compounds I, Springer, Berlin, Heidelberg, 2004, pp. 1-47.

2 A. Hauser. Ligand field theoretical considerations, Spin Crossover in Transition Metal Compounds I, Springer, Berlin, Heidelberg, 2004, pp. 49-58.

3 P. Gütlich, A. Hauser and H. Spiering, Angew. Chem., Int. Ed. Engl., 1994, 33, 2024.

4 P. Gütlich, Y. Garcia and H. A. Goodwin, Chem. Soc. Rev., 2000, 29, 419.

5 P. Gütlich, Y. Garcia and T. Woike, Coord. Chem. Rev., 2001, 219-221, 839.

6 A. Hauser, Light-induced spin crossover and the high-spin $\rightarrow$ low-spin relaxation, Spin Crossover in Transition Metal Compounds II, Springer, Berlin, Heidelberg, 2004, pp. 155-198.

7 A. Hauser, C. Enachescu, M. L. Daku, A. Vargas and N. Amstutz, Coord. Chem. Rev., 2006, 250, 1642.

8 L. Poggini, M. Milek, G. Londi, A. Naim, G. Poneti, L. Squillantini, A. Magnani, F. Totti, P. Rosa, M. M. Khusniyarov and M. Mannini, Mater. Horiz., 2018, 5, 506.

9 V. Ksenofontov, A. B. Gaspar and P. Gütlich, Pressure effect studies on spin crossover and valence tautomeric systems, Spin crossover in transition metal compounds III, Springer, Berlin, Heidelberg, 2004, pp. 23-64.

10 A. Bousseksou, F. Varret, M. Goiran, K. Boukheddaden and J. P. Tuchagues. The spin crossover phenomenon under high magnetic field, Spin Crossover in Transition Metal Compounds III, Springer, Berlin, Heidelberg, 2004, pp. 65-84.

11 C. Lefter, R. Tan, J. Dugay, S. Tricard, G. Molnár, L. Salmon, J. Carrey, W. Nicolazzi, A. Rotaru and A. Bousseksou, Chem. Phys. Lett., 2016, 644, 138.

12 S. Decurtins, P. Gütlich, C. P. Köhler, H. Spiering and A. Hauser, Chem. Phys. Lett., 1984, 105, 1.

13 S. Decurtins, P. Gutlich, K. M. Hasselbach, A. Hauser and H. Spiering, Inorg. Chem., 1985, 24, 2174. 
14 G. Chastanet, M. Lorenc, R. Bertoni and C. Desplanches, $C$. R. Chim., 2018, 21, 1075.

15 P. Gütlich, A. B. Gaspar and Y. Garcia, Beilstein J. Org. Chem., 2013, 9, 342.

16 S. Sanvito, Chem. Soc. Rev., 2011, 40, 3336.

17 N. Baadji and S. Sanvito, Phys. Rev. Lett., 2012, 108, 217201.

18 L. Poggini, M. Gonidec, J. H. González-Estefan, G. Pecastaings, B. Gobaut and P. Rosa, Adv. Electron. Mater., 2018, 4, 1800204.

19 O. Kahn and C. Jay Martinez, Science, 1998, 279, 44.

20 J.-F. Létard, P. Guionneau and L. Goux-Capes, Towards spin crossover applications, Spin Crossover in Transition Metal Compounds III, Springer, Berlin, Heidelberg, 2004, pp. 221-249.

21 S. Beniwal, X. Zhang, S. Mu, A. Naim, P. Rosa, G. Chastanet, J.-F. Létard, J. Liu, G. E. Sterbinsky, D. A. Arena, P. A. Dowben and A. Enders, J. Phys.: Condens. Matter, 2016, 28, 206002.

22 T. Miyamachi, M. Gruber, V. Davesne, M. Bowen, S. Boukari, L. Joly, F. Scheurer, G. Rogez, T. K. Yamada, P. Ohresser, E. Beaurepaire and W. Wulfhekel, Nat. Commun., 2012, 3, 938.

23 M. Bernien, D. Wiedemann, C. F. Hermanns, A. Krüger, D. Rolf, W. Kroener, P. Müller, A. Grohmann and W. Kuch, J. Phys. Chem. Lett., 2012, 3, 3431.

24 T. G. Gopakumar, F. Matino, H. Naggert, A. Bannwarth, F. Tuczek and R. Berndt, Angew. Chem., Int. Ed., 2012, 51, 6262.

25 A. Pronschinske, Y. Chen, G. F. Lewis, D. A. Shultz, A. Calzolari, M. Buongiorno Nardelli and D. B. Dougherty, Nano Lett., 2013, 13, 1429.

26 T. G. Gopakumar, M. Bernien, H. Naggert, F. Matino, C. F. Hermanns, A. Bannwarth, S. Mühlenberend, A. Krüger, D. Krüger, F. Nickel, W. Walter, R. Berndt, W. Kuch and F. Tuczek, Chem. - Eur. J., 2013, 19, 15702.

27 M. Gruber, V. Davesne, M. Bowen, S. Boukari, E. Beaurepaire, W. Wulfhekel and T. Miyamachi, Phys. Rev. B: Condens. Matter Mater. Phys., 2014, 89, 1.

28 M. Bernien, H. Naggert, L. M. Arruda, L. Kipgen, F. Nickel, J. Miguel, C. F. Hermanns, A. Kru, D. Kru, F. Tuczek and W. Kuch, ACS Nano, 2015, 9, 8960.

29 V. Davesne, M. Gruber, M. Studniarek, W. H. Doh, S. Zafeiratos, L. Joly, F. Sirotti, M. G. Silly, A. B. Gaspar, J. A. Real, G. Schmerber, M. Bowen, W. Weber, S. Boukari, V. Da Costa, J. Arabski, W. Wulfhekel and E. Beaurepaire, J. Chem. Phys., 2015, 142, 194702.

30 K. Bairagi, O. Iasco, A. Bellec, A. Kartsev, D. Li, J. Lagoute, C. Chacon, Y. Girard, S. Rousset, F. Miserque, Y. J. Dappe, A. Smogunov, C. Barreteau, M. L. Boillot, T. Mallah and V. Repain, Nat. Commun., 2016, 7, 12212.

31 R. Rüffer and A. I. Chumakov, Hyperfine Interact., 1996, 97, 589.

32 P. Gutlich, B. Eckhard and A. X. Trautwein, Mössbauer Spectroscopy and Transition Metal Chemistry, SpringerVerlag, Berlin Heidelberg, 2011.

33 A. Pronschinske, R. C. Bruce, G. Lewis, Y. Chen, A. Calzolari, M. Buongiorno-Nardelli, D. A. Shultz, W. You and D. B. Dougherty, Chem. Commun., 2013, 49, 10446.
34 L. Kipgen, M. Bernien, S. Ossinger, F. Nickel, A. J. Britton, L. M. Arruda, H. Naggert, C. Luo, C. Lotze, H. Ryll, F. Radu, E. Schierle, E. Weschke, F. Tuczek and W. Kuch, Nat. Commun., 2018, 9, 1. 35 S. Rohlf, J. Grunwald, T. Jasper-Toennies, S. Johannsen, F. Diekmann, M. Studniarek, R. Berndt, F. Tuczek, K. Rossnagel and M. Gruber, J. Phys. Chem. C, 2019, 123, 17774. 36 S. Ossinger, H. Naggert, L. Kipgen, T. Jasper-Toennies, A. Rai, J. Rudnik, F. Nickel, L. M. Arruda, M. Bernien, W. Kuch, R. Berndt and F. Tuczek, J. Phys. Chem. C, 2017, 121, 1210.

37 M. Atzori, L. Poggini, L. Squillantini, B. Cortigiani, M. Gonidec, P. Bencok, R. Sessoli and M. Mannini, J. Mater. Chem. C, 2018, 6, 8885 .

38 K. Bairagi, A. Bellec, C. Fourmental, O. Iasco, J. Lagoute, C. Chacon, Y. Girard, S. Rousset, F. Choueikani, E. Otero, P. Ohresser, P. Sainctavit, M.-L. Boillot, T. Mallah and V. Repain, J. Phys. Chem. C, 2018, 122, 727.

39 S. Rohlf, M. Gruber, B. M. Flöser, J. Grunwald, S. Jarausch, F. Diekmann, M. Kalläne, T. Jasper-Toennies, A. Buchholz, W. Plass, R. Berndt, F. Tuczek and K. Rossnagel, J. Phys. Chem. Lett., 2018, 9, 1491.

40 H. Naggert, J. Rudnik, L. Kipgen, M. Bernien, F. Nickel, L. M. Arruda, W. Kuch, C. Näther and F. Tuczek, J. Mater. Chem. C, 2015, 3, 7870.

41 B. Warner, J. C. Oberg, T. G. Gill, F. El Hallak, C. F. Hirjibehedin, M. Serri, S. Heutz, M. A. Arrio, P. Sainctavit, M. Mannini, G. Poneti, R. Sessoli and P. Rosa, J. Phys. Chem. Lett., 2013, 4, 1546.

42 A. Hauser, J. Jeftic, H. Romstedt, R. Hinek and H. Spiering, Coord. Chem. Rev., 1999, 190-192, 471.

43 M. Sorai and S. Seki, J. Phys. Chem. Solids, 1974, 35, 555.

44 E. König, G. Ritter and S. K. Kulshreshtha, Chem. Rev., 1985, 85, 219.

45 M. S. Alam, M. Stocker, K. Gieb, P. Müller, M. Haryono, K. Student and A. Grohmann, Angew. Chem., Int. Ed., 2010, 49, 1159.

46 J. A. Real, A. B. Gaspar and M. C. Muñoz, Dalton Trans., 2005, 2062.

47 S. Rat, M. Mikolasek, J. S. Costá, A. I. Chumakov, W. Nicolazzi, G. Molnár, L. Salmon and A. Bousseksou, Chem. Phys. Lett., 2016, 653, 131.

48 J. Jung, H. Spiering, Z. Yu and P. Gütlich, Hyperfine Interact., 1995, 95, 107.

49 C. P. Slichter and H. G. Drickamer, J. Chem. Phys., 1972, 56, 2142.

50 D. C. Fisher and H. G. Drickamer, J. Chem. Phys., 1971, 54, 4825.

51 C. B. Bargeron and H. G. Drickamer, J. Chem. Phys., 1971, 55, 3471.

52 P. Poganiuch, S. Decurtins and P. Guetlich, J. Am. Chem. Soc., 1990, 112, 3270.

53 A. Cini, M. Mannini, F. Totti, M. Fittipaldi, G. Spina, A. Chumakov, R. Rüffer, A. Cornia and R. Sessoli, Nat. Commun., 2018, 9, 480.

54 J. A. Real, M. C. Muñoz, J. Faus and X. Solans, Inorg. Chem., 1997, 36, 3008.

55 A. L. Thompson, A. E. Goeta, J. A. Real, A. Galet and M. Carmen Muñoz, Chem. Commun., 2004, 1390.

56 N. Moliner, L. Salmon, L. Capes, M. C. Muñoz, J.-F. Létard, A. Bousseksou, J. Tuchagues, J. J. McGarvey, A. C. Dennis, 
M. Castro, R. Burriel and J. A. Real, J. Phys. Chem. B, 2002, 106, 4276.

57 A. Galet, A. B. Gaspar, G. Agusti, M. C. Muñoz, G. Levchenko and J. A. Real, Eur. J. Inorg. Chem., 2006, 3571.

58 T. Palamarciuc, J. C. Oberg, F. El Hallak, C. F. Hirjibehedin, M. Serri, S. Heutz, J. F. Létard and P. Rosa, J. Mater. Chem., 2012, 22, 9690.

59 H. Naggert, A. Bannwarth, S. Chemnitz, T. von Hofe, E. Quandt and F. Tuczek, Dalton Trans., 2011, 40, 6364.

60 E. Ludwig, H. Naggert, M. Kalläne, S. Rohlf, E. Kröger, A. Bannwarth, A. Quer, K. Rossnagel, L. Kipp and F. Tuczek, Angew. Chem., Int. Ed., 2014, 53, 3019.

61 G. V. Smirnov, U. van Bürck, A. I. Chumakov, A. Q. R. Baron and R. Rüffer, Phys. Rev. B: Condens. Matter Mater. Phys., 1997, 55, 5811.

62 V. Potapkin, A. I. Chumakov, G. V. Smirnov, J. P. Celse, R. Rüffer, C. McCammon and L. Dubrovinsky, J. Synchrotron Radiat., 2012, 19, 559.

63 L. Chen and Y. De-ping, Mössbauer Effect in Lattice Dynamics: Experimental Techniques and Applications, Wiley-VCH Verlag, Weinheim, Germany, 2007.
64 F. Remacle, F. Grandjean and G. J. Long, Inorg. Chem., 2008, 47, 4005.

65 X. Zhang, T. Palamarciuc, P. Rosa, J. F. Létard, B. Doudin, Z. Zhang, J. Wang and P. A. Dowben, J. Phys. Chem. C, 2012, 116, 23291.

66 W. Kuch and M. Bernien, J. Phys.: Condens. Matter, 2017, 29, 023001.

67 K. Senthil Kumar and M. Ruben, Coord. Chem. Rev., 2017, 346, 176.

68 M. Ruben and K. S. Kumar, Sublimable Spin Crossover Complexes: From Spin-State Switching to Molecular Devices, Angew. Chem., Int. Ed., 2020, DOI: 10.1002/anie.201911256.

69 S. Ossinger, C. Näther, A. Buchholz, M. Schmidtmann, S. Mangelsen, R. Beckhaus, W. Plass and F. Tuczek, Spin Transition of an Iron(II) Organoborate Complex in Different Polymorphs and in Vacuum-Deposited Thin Films: Influence of Cooperativity, Inorg. Chem., 2020, DOI: 10.1021/ acs.inorgchem.9b03354.

70 L. Poggini, M. Gonidec, R. K. C. Balasubramanyam, L. Squillantini, G. Pecastaings, A. Caneschi and P. Rosa, J. Mater. Chem. C, 2019, 7, 5343. 